ISSN: 2146-3042

DOI: $10.25095 /$ mufad.673729

\title{
BİST Altın Fiyatları Serisinin Markov Rejim Değişim Modeli İle
} Analizi*

\author{
Onur BARCA*
}

Özer ARABACI**

\section{ÖZET}

Altın, fiziksel ve kimyasal özellikleri nedeniyle, endüstriyel kullanımının yanında yatırım aracı olarak da kullanılan değerli bir madendir. Merkez bankaları tarafindan rezerv aracı olarak kullanılan altın, aynı zamanda borsalarda yoğun bir şekilde işlem görmektedir. Bu çalışmada, Borsa İstanbul (BISST) altın getirilerinin doğrusal olmayan yapısı, Markov Rejim Değiş̧im Modeli ile analiz edilmiștir. Analizde getiri dönemleri üç rejimli bir model ile belirlenmiştir. Analiz sonuçlarına göre, altın getirilerinin en yüksek olduğu dönemler, volatilitenin en yüksek olduğu dönemlerin öncesinde ve sonrasında yer almaktadır. Ayrıca altın getiri serisinde volatilitenin en düşük olduğu rejim, en büyük süre değişkenine sahiptir. Bu da altının bir yatırım aracı olarak oynaklığının çok yüksek olmadığını ve bu nedenle uzun dönem için güvenilir bir yatırım aracı olduğunu göstermektedir.

Anahtar Kelimeler: Markov Rejim Değiş̧im Modeli, Altın Fiyatları, Volatilite

JEL Sınıflandirması: C24, G11

\section{An Analysis of BiST Gold Prices With The Markov Switching Model}

\section{ABSTRACT}

Due to its physical and chemical properties, gold is a valuable mine used as an financial investment tool in addition to industrial use. Gold, which asset used as a reserve tool by central banks, is also heavily traded in stock exchanges. In this study, the non-linear structure of Borsa Istanbul (BIST) gold returns analyzed with the Markov Regime Switching Model. In the analysis, the winning and losing periods of gold returns determined by a three-regime model. According to the results of the analysis, the highest return on gold located, before and after the highest volatility period. In addition, the regime with the lowest volatility has the highest time value. This result shows that the volatility of gold is not very high, and it is a reliable investment tool.

Keywords: Markov Switching Model, Gold Price, Volatility

Jel Classification: C24, G11

\footnotetext{
* Makale Gönderim Tarihi: 10.06.2019, Makale Kabul Tarihi: 06.08.2019, Makale Türü: Araştırma Makalesi

*Uludağ Üniversitesi, Sosyal Bilimler Fakültesi, onurbarca@ gmail.com, Orcid ID: 0000-0001-7339-3683

** Doç. Dr., Uludağ Üniversitesi İktisadi ve İdari Bilimler Fakültesi, ozerarabaci@uludag.edu.tr, Orcid ID: 00000002-5434-2458
} 


\section{GíRiş}

Altın endüstri hammaddesi olarak; kuyumculuk, elektronik ve sağlık sektörlerinde kullanım alanına sahip olmasının yanı sıra, finansal bir enstrüman olarak da oldukça yaygın bir şekilde kullanılmaktadır. Bu nedenle altın fiyatlarında yaşanan oynaklıklar birçok sektörü, emtia yatırımcısını ve finans piyasalarını etkilemektedir (Evci vd., 2016: 68). Finansal piyasalardaki belirsizliklerin artmasına bağlı olarak altın fiyatlarının getirilerinde özellikle volatilite açısından farklılaşmalar yaşanabilmektedir. Diğer tüm finansal yatırım araçlarında olduğu gibi piyasanın görece daha durağan seyrettiği dönemlerde, altın fiyatlarındaki değişimin tahmin edilebilirliği, oynaklığın ön planda olduğu dönmelere göre daha yüksektir. Oynak piyasalardaki yüksek seviyedeki volatilite ya da diğer bir değişle varyansın yüksek olması, bu piyasalarda altın fiyatlarındaki değişimin tahmin edilmesini zorlaştırmaktadır. Bundan dolayı, altın fiyatlarındaki rejim değişiminin tespiti, riskin ve olası portföy kaybının kontrolünü sağlayabilmek için önem taşımaktadır (Tuna vd., 2014: 28).

Öte yandan finansal zaman serisi analizlerinde kullanılan doğrusal zaman serisi modellerinin kısıtları nedeniyle finansal veri setlerinin sahip olduğu bazı anahtar özelliklerin doğrusal dışı zaman serisi modelleriyle daha doğru bir şekilde modellenebileceği ya da diğer bir ifade ile doğrusal modellerin bu alandaki uygunsuzluğu, son y1llarda sıklıkla dile getirilen bir gerçektir. Bu anlamda öne çıkan doğrusal dışı modeller, eşik değer modelleri, yumuşak geçiş modelleri, Markov rejim değişim modelleri, yapay sinir ağları vs. olarak sıralanabilir. $\mathrm{Bu}$ modeller içerisinde Markov rejim değişim modelleri hem rejim değişimlerine doğrudan gözlemlenemeyen bir durum değişkeni vasitasıyla karar vermesi hem de rejim geçiş olasılıklarının hesaplanmasına izin vermesi nedeniyle ayrı bir yere ve öneme sahiptir. Örneğin Guidolin (2011), Markov rejim değişim modellerinin, veri setine uygunluk anlamında doğru rejim değişimlerine izin vermesi, finans teorisi 1 şı̆̆ında güçlü hipotez testlerinin yapılabilmesine imkan tanıması ve tahmin performanslarının etkinliğinin yüksek olması nedeniyle farklı ve aynı zamanda da haklı bir dikkati üzerine çektiğini vurgulamaktadır.

Bu çalışmada, üç rejimli bir Markov rejim değişim modeli kullanılarak, Borsa İstanbul (BİST) altın getiri serisi analiz edilmiştir. Çalışmada, yüksek ve düşük getirili rejimlerin belirlenmesi, bu rejimler için geçiş olasılıklarının ve süre değişkenlerinin hesaplanması amaçlanmıştır. Çalışma beş bölümden oluşmaktadır. Birinci bölümü giriş bölümü olup, ikinci bölümde literatür taramasına yer verilmiştir, üçüncü bölümde analizde kullanılan yöntem tanıtılmış ve dördüncü bölümde de ampirik bulgular sunulmuştur. Son bölümünde ise genel bir değerlendirmeye yer verilmiştir.

\section{LITERATÜR TARAMASI}

Markov rejim değişim modellerine ait ilk çalışmalar Quandt (1958), Goldfeld, Quandt (1973) ve Hamilton'a (1989) dayanmaktadır. Hamilton 1989 ve 1990 yıllarında yaptığ çalışmalarında, geliştirdiği Markov rejim değişim otoregresif (MS-AR) modeli ile ABD ekonomisindeki konjonktürel dalgalanmaların, genişleme ve daralma olmak üzere iki rejimden meydana geldiğini ve rejimler arasında geçiş genliğin olduğunu belirtmiştir. Markov rejim değişim modelleri büyük ölçüde Hamilton'un bu çalışmalarıyla popülerlik kazanmış ve daha sonra Krolzing' in (1997, 1998, 2000, 2001) çalışmalarıyla Markov rejim değişim otoregresif (MS-VAR) modelleri geliştirilmiştir. Bu aşamadan sonra MS modelleri finansal serilerin modellemesinde geniş çaplı uygulama alanı bulmuştur. 
Yarmohammadi, Mostafaei ve Safaei (2012) tarafından yapılan çalışmada, 1996-2009 dönemi için yedi farklı zaman serisi modeli kullanılarak İran döviz kuru serisi analiz edilmiştir. Analizde kullanılan modeller AIC bilgi kriterine göre sıralanmıştır. En küçük AIC bilgi kriterine sahip olan MS-AR modelinin, İran döviz kuru serisinin analizi için en uygun model olduğu belirtilmiştir. Koy (2017) tarafindan yapılan çalışmada, 2005-2016 dönemi için BİST 30 endeksi, Markov Rejim Değişim Otoregresif Model ile analiz edilmiş ve endeks daralma, 1lımlı büyüme ve genişleme olmak üzere üç rejimde incelenmiştir. Analiz sonuçlarına göre, 1 lımlı büyüme rejimindeki fiyat değişimlerinin, genişleme dönemine göre daha yüksek olduğu belirlenmiştir. Atış ve Erer (2018) tarafından yapılan çalışmada, 2002:12016:12 döneminde Markov Rejim Değişim modeli ile Türkiye'de ayı ve boğa piyasaları açısından hisse senedi getirilerinin ve oynaklığının para politikasına asimetrik tepkisi analiz edilmiştir. Analiz sonuçlarına göre, para politikasının boğa piyasasında daha etkin olduğu görülmüştür.

Öte yandan, altın fiyatlarının modellenmesi üzerine yapılan çalışmalarda da Markov Rejim Değişim modelleri sıklıkla kullanılmıştır. Örneğin, Evci, Şak ve Karaağaç (2016), tarafından yapılan çalışmada, altın piyasasının kazandıran ve kaybettiren dönemleri Markov Rejim Değişim Otoregresif Model ile belirlenmiştir. Bu çalışmada, Temmuz 1995-Temmuz 2015 tarihleri arasındaki dönem, Borsa İstanbul altın ve Londra altın piyasasına ilişkin aylık altın getiri serileri kullanılarak analiz edilmiştir. Analizde, Borsa İstanbul altın getirilerinin, Londra altın getirisinin iki ay gecikmeli değerinden etkilendiği tespit edilmiştir. Lucey ve O’Connor (2013), Białkowski, Bohl, Stephan, ve Wisniewski (2015), tarafindan yapılan çalışmalarda, Markov rejim değişim modeli durağanlık çerçevesinde değerlendirilerek kullanılmış ve altın fiyatlarında bir varlık balonunun oluşup oluşmadığı incelenmiştir. Analiz sonuçlarına göre yapılan iki çalışmada da altın fiyatlarında balon oluştuğuna ilişkin bulguya ulaşılamamıştır.

Ayrıca, volatilite modellemesi konusunda da MS modellerine dayalı çalışmalara rastlanmaktadır. Örneğin, Sopipan, Sattayatham, ve Premanode (2012), 2007-2011 dönemini kapsayan çalışmalarında altın piyasasındaki oynaklığı, MS-GARCH modeli ile günlük altın fiyatlarını kullanarak tahmin etmişlerdir. Analiz sonuçlarına göre oynaklığı tahmin etmede, MS-GARCH modelinin standart GARCH modellerinden daha iyi performans gösterdiği tespit edilmiştir.

Diğer taraftan, çok değişkenli zaman serisi modellerinin kullanıldığı çalışmalarda da Markov Rejim Değişim modelleri kullanılmaktadır. Örneğin, Wai, Ismail, ve Kun (2014), tarafından yapılan çalışmada, altın fiyatlarının borsa endeksine etkisi Markov Rejim Değişim Hata Düzeltme Modeli ile analiz edilmiştir. Elde edilen bulgulara göre; altın fiyatının Malezya, Tayland ve Endonezya borsaları ile pozitif bir ilişkiye sahip olduğunu ve MSIHVECM modelinin MSI-VECM modeline göre yumuşatılmış rejim geçiş olasılıklarını tespit etmede daha başarılı olduğu belirtilmiştir. Akgün, Bildirici, ve Özdemir (2015) ise, petrol fiyatlarındaki değişimin borsa endeksi ile altın fiyatları üzerindeki etkisi üç rejimli bir Markov Rejim Değişim Bayesian Vektör Otoregresif Model ile analiz edilmiştir. 1986-2013 yılları arasında aylık verilerden oluşan çalışmada, petrol fiyatlarındaki değişimin altın fiyatlarını ve borsa endeksini etkilediği ve bu etkinin rejime göre değiştiği belirlenmiştir. 


\section{YÖNTEM}

Doğrusal olmayan zaman serileri analizinde, doğrudan gözlemlenebilen bir değişkenin etkisiyle oluşan dalgalanma dönemleri arasında geçişin olduğu yapılar eşik modelleri kullanılarak analiz edilmektedir. Öte yandan, gözlemlenemeyen stokastik bir değişkenin etkisiyle, rejimler arasında geçişlerin olduğu yapı ise Markov rejim değişim modelleriyle ele alınmaktadır (Koy, 2017: 83). Son yıllarda literatürde çok sayıda doğrusal olmayan zaman serisi modelleri ile ilgili çalışmalar olmasının yanında Markov rejim değişim modellerinin daha ön planda olması ve daha fazla tercih edilmesinin bir nedeni bu modellerin ele alınan serinin yapısındaki değişimi dikkate alması ve olasılıksal çıkarımlar yapabilmeye de izin vermesidir (Büyükyılmaz, 2015: 13).

Birinci dereceden bir otoregresif model, tek bir $\mathrm{Y}_{\mathrm{t}}$ değişkeni olarak tanımlanan bir zaman serisi için şu şekilde açıklanabilir:

$$
\mathrm{Y}_{\mathrm{t}}=\mathrm{c}+\Phi \mathrm{y}_{\mathrm{t}-1}+\varepsilon_{\mathrm{t}}
$$

Burada, $\varepsilon_{\mathrm{t}} \sim \mathrm{N}\left(0, \sigma^{2}\right)$ ve $\mathrm{t}=1,2,3, \ldots, \mathrm{T}^{\prime}$ dir.

Eğer $t_{0}$ zamanında serinin ortalamasında anlamlı bir değişiklik olduğu biliniyorsa, seriyi $t_{0}$ zamanından önce ve sonra olmak üzere iki ayrı denkleme ayırmak anlamlı olacaktır. Ancak bu veri setinin küçülmesine ve modelde istatistiksel açıdan bir etkinlik kaybına neden olacaktır (Türkmen, 2017: 112). Daha açık bir şekilde, $t_{0}$ ortalamada değişimin olduğu zamanı göstermek üzere, (1) no'lu modeli şu şekilde yazabiliriz.

$$
\begin{array}{ll}
\mathrm{Y}_{\mathrm{t}}=\mathrm{c}_{1}+\Phi \mathrm{y}_{\mathrm{t}-1}+\varepsilon_{\mathrm{t}}, & t<t_{0} \\
\mathrm{Y}_{\mathrm{t}}=\mathrm{c}_{2}+\Phi \mathrm{y}_{\mathrm{t}-1}+\varepsilon_{\mathrm{t}}, & t>t_{0}
\end{array}
$$

Kesme teriminde $c_{1}$ 'den $c_{2}$ 'ye olan değişim değeri, modelin öngörü başarısını arttırırken, olasılık kuralları gereği veri oluşturmakta yetersiz kalınabileceğini ifade etmektedir (Hamilton, 2005: 1). Bu durumda, denklem (2) ve denklem (3)'deki her iki modeli de kapsayan ve veri kaybının yaşanmasını engelleyen daha geniş bir model şu şekilde yazılabilir:

$$
\mathrm{Y}_{\mathrm{t}}=c_{s_{\mathrm{t}}}+\Phi \mathrm{y}_{\mathrm{t}-1}+\varepsilon_{\mathrm{t}}
$$

Burada, eğer seri birinci rejimde bulunuyorsa $s_{t}=1$, ikinci rejimde bulunuyorsa $s_{t}=2$ değerini almaktadır. Buradaki rejim veya durum değişkeni $s_{t}$, Markov Rejim Değişim modelinde doğrudan gözlemlenememekte sadece iktisadi veya finansal zaman serisi $\mathrm{Y}_{\mathrm{t}}$ gözlemlenebilmektedir (Bildirici vd., 2010: 75).

Böyle bir durum Markov Zinciri yardımıyla oluşturulan bir yapıda daha net bir şekilde ele alınabilmektedir. Bu yapı, Markov rejim değişim modellerinin de temelini oluşturur. Markov rejim değişim modelleri, Markov zinciri aracılığıyla rejimler arasındaki değişimi belirleyen ve doğrudan gözlemlenemeyen $s_{t}$ durum değişkeninin davranışını modellemek için kullanılmaktadır (Bildirici vd., 2010: 56-57). 
Durum değişkeni $s_{t},(\mathrm{t}=1,2,3, \ldots, \mathrm{N})$ tamsayı değeri alan, rassal bir değişken olsun. Birinci dereceden bir Markov zinciri aşağıdaki gibi ifade edilebilir:

$$
\operatorname{Pr}\left(\mathrm{s}_{\mathrm{t}}=\mathrm{j} \mid \mathrm{s}_{\mathrm{t}-1}=\mathrm{i}, \mathrm{s}_{\mathrm{t}-2}=\mathrm{k}, \ldots, y_{t-1}, y_{t-2}, \ldots\right)=\operatorname{Pr}\left(\mathrm{s}_{\mathrm{t}}=\mathrm{j} \mid \mathrm{s}_{\mathrm{t}-1}=\mathrm{i}\right)=\mathrm{P}_{\mathrm{ij}}
$$

Burada $y_{t}$, otoregresif katsayı $\Phi$ 'ye, kesim noktaları $c_{1}$ ve $c_{2}$ 'ye, ve ayrıca iki aşamalı geçiş olasılıkları $p_{11}$ ve $p_{22}$ 'ye bağlıdır. Öte yandan $y_{t}$ 'nin olasılık kuralları ile açıklanabilmesi için $\sigma^{2}$ 'nin normal dağılması gerekmektedir (Büyükyılmaz, 2015: 15).

Daha net bir ifade ile otoregresif bir modelin, Markov Rejim Değişim Otoregresif Modelle ilişkisi şu şekilde kurulabilir. $Y_{t}$ şeklinde tanımlanan bir zaman serisi için AR(1) süreci şöyle tanımlansın,

$$
\mathrm{Y}_{\mathrm{t}}=\mathrm{C}_{1}+\Phi \mathrm{y}_{\mathrm{t}-1}+\varepsilon_{\mathrm{t}}
$$

$Y_{t}$ serisi için serinin ortalamasını değiştirecek bir değişim olduğunda $A R(1)$ süreci farklı bir sabit ile gösterilir.

$$
\mathrm{Y}_{\mathrm{t}}=\mathrm{C}_{2}+\Phi \mathrm{y}_{\mathrm{t}-1}+\varepsilon_{\mathrm{t}}
$$

1 ve 2 numaralı eşitliklerden hareketle $Y_{t}$ serisi ise iki rejimli şu şekilde ifade edilebilir. (Tsay, 2006: 135)

$$
\mathrm{Y}_{\mathrm{t}}= \begin{cases}C_{1}+\sum_{\mathrm{I}=1}^{p} \Phi_{1, i} y_{t-i}+\varepsilon_{1 t} & \text { ĕger } s_{t}=1, \\ C_{2}+\sum_{\mathrm{I}=2}^{p} \Phi_{1, i} y_{t-i}+\varepsilon_{2 t} & \text { e ğer } s_{t}=2,\end{cases}
$$

Burada, seri birinci rejimdeyse $s_{t}=1$, ikinci rejimdeyse $s_{t}=2$ değerini alacaktı. İki rejimli bir yapıda geçiş olasılıkları ise şu şekilde gösterilebilir:

$$
P=\left|\begin{array}{ll}
P_{11} & P_{12} \\
P_{21} & P_{22}
\end{array}\right|
$$

Ayrıca geçiş olasılıkları rejimlere bağlı olarak şu şekilde ifade edilebilir,

$$
\begin{aligned}
& \mathrm{P}_{11}=\left(S_{t}=1 \mid S_{t-1}=1\right)=\mathrm{p} \\
& \mathrm{P}_{12}=\left(S_{t}=2 \mid S_{t-1}=1\right)=1-\mathrm{p} \\
& \mathrm{P}_{21}=\left(S_{t}=1 \mid S_{t-1}=2\right)=\mathrm{q} \\
& \mathrm{P}_{22}=\left(S_{t}=2\left[S_{t-1}=2\right)=1-\mathrm{q}\right.
\end{aligned}
$$

$Y_{t}$ serisi için, $p$; birinci rejimde kalma olasılı̆̆ını, 1-p; birinci rejimden ikinci rejime geçiş olasılı̆̆ını, q; ikinci rejimden birinci rejime geçiş olasılığını, 1-q ise ikinci rejimde kalma olasılığını vermektedir. Geçiş olasılıklarının toplamları bire eşittir ve bu olasılıklar 
negatif olamazlar. Birinci rejimde kalma süresi, $\frac{1}{1-P_{11}}$ ikinci rejimde kalma süresi ise, $\frac{1}{1-P_{22}}$ formülleri kullanılarak hesaplanabilir (Hamilton, 1989: 360).

Sonuç olarak Markov Rejim Değişim modeli,

$$
\mathrm{Y}_{\mathrm{t}}=\mu_{s_{\mathrm{t}}}+\mathrm{u}_{\mathrm{t}} \text { ve } \mathrm{u}_{\mathrm{t}} \sim \text { iid }\left(0, \sigma^{2}\right)
$$

şeklinde ifade edilebilir.

$\mathrm{Bu}$ model rejimin koşullu ortalamaya $\left(\mu_{\mathrm{t}}\right)$ göre değiştiği $(\mathrm{MSM})$ ve sabite $\left(\mathrm{C}_{\mathrm{st}}\right)$ göre değiştiği (MSI) modelleri olarak ikiye ayrılır (Koy, 2017: 77).

MSI modelleri,

$$
\mathrm{Y}_{\mathrm{t}}=C_{\mathrm{s}_{\mathrm{t}}}+\Phi \mathrm{Y}_{\mathrm{t}-1}+\mathrm{u}_{\mathrm{t}}
$$

şeklinde olup $Y_{t}$ 'nin sabit terimi rejimle birlikte değişmektedir.

MSM modelleri ise,

$$
\mathrm{Y}_{\mathrm{t}}-\mu_{s_{\mathrm{t}}}=\Phi\left(\mathrm{Y}_{\mathrm{t}-1}-\mu_{s_{\mathrm{t}}-1}\right)+\mathrm{u}_{\mathrm{t}}
$$

şeklinde olup $\mathrm{Y}_{\mathrm{t}}^{\prime}$ nin ortalaması rejim ile birlikte değişmektedir.

Rejimin (m), otoregresif sürecin ise p ile gösterildiği bir MSIH(m)AR(p) modeli ise şu şekilde ifade edilebilir (Clements \& Krolzig, 1997: 14).

$$
\mathrm{Y}_{\mathrm{t}}=\mathrm{C}+\sum_{i=1}^{p} \Phi_{\mathrm{i}} \mathrm{Y}_{\mathrm{t}-\mathrm{i}}+\varepsilon_{\mathrm{t}}
$$

Burada, $\mathrm{Y}_{\mathrm{t}}$ gözlemlenebilen bir zaman serisi olmak üzere $\left[\mathrm{Y}_{1}, \mathrm{Y}_{2}, \ldots \mathrm{Y}_{\mathrm{t}}\right]^{\prime}$ ve kesme teimleri ile durum vektörleri de $\left[\mathrm{c}_{1}\left(\mathrm{~s}_{\mathrm{t}}\right), \mathrm{c}_{2}\left(\mathrm{~s}_{\mathrm{t}}\right), \ldots . \mathrm{c}_{\mathrm{t}}\left(\mathrm{s}_{\mathrm{t}}\right)\right]^{\prime}$ şeklinde olmak üzere rejime bağ $\mathrm{l}_{1}$ olarak değişir. $\varepsilon_{\mathrm{t}}=\left[\varepsilon_{1 \mathrm{t}}, \varepsilon_{2 \mathrm{t}}, \ldots \varepsilon_{\mathrm{T}}\right]^{\prime}$ ise bir Gauss beyaz gürültü vektörüdür ve $\varepsilon_{\mathrm{t}} \sim$ NID $\left(0, \sigma^{2}\left(\mathrm{~s}_{\mathrm{t}}\right)\right)$ olup, gözlemlenemeyen ayrı rejim değişkeni olan $\mathrm{s}_{\mathrm{t}}$ 'ye bağlıdır.

Açıktır ki, otoregresyon derecesinin sıfıra eşit olması halinde MSI ve MSM modellerinin özellikleri birbirine eşit olacaktır. Sabite göre değişen MSI modellerinde rejimler arası geçiş daha yumuşak iken, ortalamaya göre değişen MSM modellerinde geçiş daha keskindir (Bildirici vd., 2010: 76). Finansal zaman serilerinde çoğunlukla rejimler arasındaki geçiş yumuşak olup, rejimleri birbirinden ayırmada varyans önemli bir faktör olmaktadır. Geleceğe yönelik fiyat beklentilerinin iyimser bir ortamda seyrettiği dönemlerde (boğa piyasası), fiyattaki değişimlerin hızlandığ Geleceğe yönelik fiyat beklentilerinin kötümser bir ortamda seyrettiği dönemlerde (ay1 piyasas1) ise iyimser dönemlere göre, volatilitede daha yüksek artışlar görülmektedir (Koy, 2017: 77-78). 


\section{VERİ SETİ VE AMPIRIIK BULGULAR}

Çalışmada kullanılan BİST altın fiyat serisine, TC Merkez Bankası elektronik veri dağıtım sistemi (EVDS)'den ulaşılmıştır. Çalışmanın veri setini, 01.01.2007 - 29.06.2018 tarihleri arasındaki günlük Borsa İstanbul altın kapanış fiyatları (USD/Ons) oluşturmaktadır. Altın fiyatlarına ilişkin getiriler $\left(\log \left(\mathrm{P}_{t} / \mathrm{P}_{\mathrm{t}-1}\right)\right)$ formülü kullanılarak hesaplanmıştır. Ele alınan dönem için BİST altın getiri serisine ilişkin zaman yolu grafiği aşağıdaki gibidir. BİST altın getiri serisine ait grafĭği incelediğimizde volatilitenin zaman içinde değiştiği, özellikle 20082009 küresel kriz döneminde volatilitenin arttığı rahatlıkla söylenebilir. Ayrıca BİST altın getiri serisinin volatilite kümelenmelerine sahip olduğu da görülmektedir.

\section{Grafik 1: BİST Altmn Getiri Serisi}

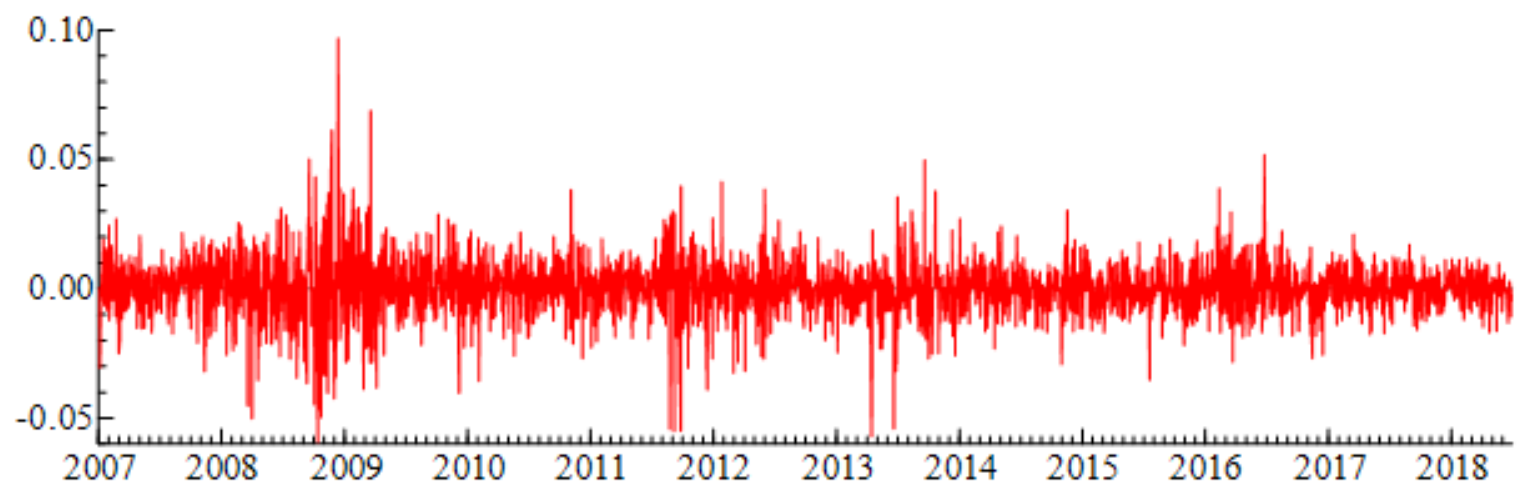

Betimsel istatistikler incelediğinde, BİST altın getiri serisinin ortalamasının 0.0002 ve standart sapmasının 0.0110 olduğu görülmektedir. Standart sapma değerinin küçük olması serideki değişkenliğin genelde düşük olduğunu göstermektedir. Ayrıca serinin olasılık dağılımındaki asimetrisini gösteren çarpıklık katsayısı dikkate alındığında, serinin hafif sağa çarpık olduğu görülmektedir. Basıklık katsayısı ise 3'ten büyük olduğu için getiri serisinin dağılımının dik olduğunu söylenebilir. Boş hipotezinde normal dağılımın olduğu Jarque-Bera testinin test istatistiğine göre ise getiri serisinin normal dağılmadığı sonucuna ulaşılmaktadır.

Tablo 1. Betimsel İstatistikler

\begin{tabular}{ccccccc}
\hline \hline Değişken & Gözlem & Ortalama & Standart Sapma & Çarpıklık & Basıklık & Jarque-Bera \\
\hline BİST Altın & 3000 & 0.00022 & 0.0110 & 0.0102 & 8.6920 & 4048.653 \\
{$[0.000]$} & \\
\hline \hline
\end{tabular}

Not: Köşeli parantez içindeki değer "p value" değerini göstermektedir

BİST altın getiri serisinin durağan bir yapıya sahip olup olmadığı Genişletilmiş Dickey-Fullar Testi (ADF) ve Phillips Perron (PP) birim kök testleriyle incelenmiştir ve sonuçlar tablo 2'de sunulmuştur. ADF ve PP birim kök testlerinde hesaplanan test istatistiklerine göre, serinin birim kök içerdiği boş hipotezi $\% 1$ anlamlllık düzeyinde reddedilmektedir. Buna göre, getiri serisinin istatistiksel olarak anlamlı bir şekilde durağan olduğu sonucuna ulaşılmıştır. 
Tablo 2. Birim Kök Testleri

\begin{tabular}{cc}
\hline \hline ADF Birim Kök Testi & PP Birim Kök Testi \\
\hline$t$-istatistiğ $i$ & $t$-istatistiği \\
$-54.41168 * * *$ & $-54.41231^{* * *}$ \\
\hline \hline
\end{tabular}

Not: ***\%1 düzeyinde anlamlılığı ifade etmektedir. ADF testi için kesmeli model ve gecikme uzunluğu bilgi kriterlerine göre 0 olarak seçilmiştir. PP testi için Bandwidth bilgi kriterlerine göre 8 olarak seçilmiştir.

$\mathrm{Bu}$ aşamadan sonra BIST altın getiri serisinin analizinde doğrusal olmayan zaman serisi yöntemlerinden biri olan Markov rejim değişim modeli kullanılmıştır. Getiri serisi için en uygun Markov rejim değişim modelinin belirlenmesinde, Akaike (AIC), Shwartz (SC), Hannan Queen (HQ) bilgi kriterleri ve log-olabilirlik oranından yararlanılmıştır. Bilgi kriterlerine göre en kü̈cük ve log-olabilirlik oranına göre en büyük değere sahip model, rejim ile birlikte sabit terimlerin (I) ve varyansın (H) değiştiği MSIH(3)-AR(0) modelidir.

Tablo 3. Bilgi Kriterlerine Göre Uygun Model Seçimi

\begin{tabular}{ccccc}
\hline \hline Model & AIC & HQ & SIC & Log-olabilirlik oranı \\
\hline MSIH(2)-AR(0) & $-6,3697$ & $-6,3653$ & $-6,3576$ & 9557,2995 \\
MSIH(2)-AR(1) & $-6,3681$ & $-6,3623$ & $-6,3521$ & 9553,7478 \\
MSIH(2)-AR(2) & $-6,3666$ & $-6,3594$ & $-6,3465$ & 9550,3085 \\
MSIH(2)-AR(3) & $-6,3652$ & $-6,3565$ & $-6,3411$ & 9547,0541 \\
MSIH(3)-AR(0) & $\mathbf{- 6 , 3 9 4 8}$ & $\mathbf{- 6 , 3 8 6 2}$ & $\mathbf{- 6 , 3 7 0 7}$ & $\mathbf{9 6 0 1 , 0 4 3 2}$ \\
MSIH(3)-AR(1) & $-6,3679$ & $-6,3846$ & $-6,3679$ & 9597,5009 \\
MSIH(3)-AR(2) & $-6,3651$ & $-6,3831$ & $-6,3431$ & 9594,0788 \\
MSIH(3)-AR(3) & $-6,3647$ & $-6,3822$ & $-6,3412$ & 9590,0463 \\
\hline \hline
\end{tabular}

Markov rejim değişim modeli için, getiri serisinin doğrusal olmama özelliğinin test edilmesinde Davies (1978) testi ve LR testleri kullanılmıştır. Bu testler Markov rejim değişim modelinin, doğrusal modele kıyasla daha iyi bir performansa sahip olup olmadığını anlayabilmek için kullanılmaktadır. Davies ve LR test istatistiklerine göre, serinin doğrusal olduğunu ileri süren $\mathrm{H}_{0}$ hipotezi \%1 anlamlılık düzeyinde reddedilmektedir. Bu sonuçlara göre, BİST altın getiri serisinin doğrusal olmayan bir yapı sergilediği ve doğrusal olmayan zaman serisi modellerinden biri olan Markov rejim değişim modeli ile modellenmesinin uygun olduğu görülmektedir. Normallik ve Portmanteau testlerinin sonuçları da model için temel varsayımlarının sağlandığını göstermektedir. 
Tablo 4. MSIH(3)-AR(0) Varsayımlarına İlişkin Testler

\begin{tabular}{ccc}
\hline \hline Model & Linearity LR-test $\chi^{2}(\mathbf{1 0})$ & $\begin{array}{c}\text { Davies testi } \\
\text { olasılık değeri }\end{array}$ \\
\hline MSIH(3)-AR(0) & $698.67[0.0000]$ & {$[0.0000]$} \\
\hline Varsayımlar & Test istatistiği & \\
\hline Log-olabilirlik oran1 & $9601.04[0.0000]$ \\
Normallik testi $\chi^{2}(2)$ & $1.6168[0.4456]$ & \\
Portmanteau testi (54) & $49.782[0.6377]$ \\
\hline \hline
\end{tabular}

Not: Köşeli parantez içindeki değer "p value" değerlerini göstermektedir

MSIH(3)-AR(0) modeli tahmin sonuçlarına göre; katsayısı negatif olan rejim 3 daralma rejimi dönemini, katsayıları pozitif olan rejim 1 ve 2 ise genişleme rejimi dönemini göstermektedir. Üçüncü rejim, volatilitenin en yüksek olduğu ve getirilerin negatif olduğu rejimdir. Genişleme rejimi olarak adlandırdığımız rejim 1 ve 2'yi karşılaştırdığımızda, ikinci rejimin getirisinin ve volatilitesinin birinci rejime göre daha yüksek olduğu görülmektedir. $\mathrm{Bu}$ sonuçlara göre; volatilitenin artmasıyla birlikte riskin de arttığı varsayımı altında, rejim 1 volatilitenin ve getirinin en düşük olduğu, bununla birlikte riskin de en az olduğu rejim olarak tanımlanabilir. Rejim 2 volatilitenin, getirinin ve riskin birinci rejime göre daha yüksek olduğu, rejim 3 ise volatilitenin ve riskin en yüksek olduğu, bununla birlikte getirinin de negatif olduğu rejimdir.

Tablo 5: Markov Rejim Değişim Modeli Tahmin Sonuçları: MSIH(3)-AR(0)

\begin{tabular}{cccc}
\hline \hline Değişkenler & Katsayı & Standart Hata & t-istatistiğgi \\
\hline Sabit (Rejim 1) & 0.00021 & 0.00019 & 1.09 \\
Sabit (Rejim 2) & 0.00074 & 0.00045 & 1.66 \\
Sabit (Rejim 3) & -0.00225 & 0.00208 & -1.09 \\
\hline Değişkenler & & Katsayı & Standart Hata \\
\hline Sigma (Rejim 1) & 0.0074 & 0.0002 \\
Sigma (Rejim 2) & 0.0110 & 0.0007 \\
Sigma (Rejim 3) & 0.0253 & 0.0022 \\
\hline \hline
\end{tabular}

Modelin rejim geçiş olasılıklarına bakarsak, altın getiri serisi rejim 1'de iken tekrardan 1. rejimde kalma olasılığ 0.98 ; rejim 2'de iken 2. rejimde kalma olasıllı̆g 10.95 ; rejim 3'te iken 3. rejimde kalma olasılığı 0.80 olduğu görülmektedir. Üç rejim içinde bir dönem sonra aynı rejimde kalma olasılıklarının yüksek olması, modelde üç rejiminde birbirinden net bir şekilde ayrıldığını göstermektedir. Rejim 1'deyken rejim 2'ye geçiş olasılığ 10.01 iken rejim 2'den rejim 1'e geçiş olasıllı̆ 1 yine 0.01 'dir. Aynı şekilde rejim 1'den rejim 3'e geçiş olasıllı̆ 1 ve rejim 3'ten rejim 1'e geçiş olasılığg 0.01 'dir. Rejim 2'den, rejim 3'e geçiş olasilığ 10.19 iken rejim 3'ten rejim 2'ye geçiş olasilı̆ğ 0.04'tür. 
Tablo 6. Rejim Olasılıkları Matrisi

\begin{tabular}{cccc}
\hline \hline & Rejim 1 & Rejim 2 & Rejim 3 \\
\hline Rejim 1 & 0.98 & 0.01 & 0.01 \\
Rejim 2 & 0.01 & 0.95 & 0.19 \\
Rejim 3 & 0.01 & 0.04 & 0.80 \\
\hline Tüm Örneklem & 1 & 1 & 1 \\
\hline \hline
\end{tabular}

Modelde, toplam gözlemin \%56's1 (1680 gözlem) 1. rejimde, \%38'i (1140 gözlem) 2. rejimde, \%6's1 (180 gözlem) 3. rejimde yer almaktadır. Rejimde kalma süreleri, rejim 1'in ortalama 122 gün (4 ay), rejim 2'nin 30 gün (1 ay), rejim 3'ün 5 gün olarak hesaplanmıştır. Bu sonuçlara göre, BİST altın getiri serisi büyük ölçüde 1. rejimde yani volatilitenin en düşük olduğu rejimde kalmaktadır.

Tablo 7. Rejim Özellikleri

\begin{tabular}{lccc}
\hline \hline & Gözlem Sayısı & Süre (gün) & Yüzde \\
\hline Rejim 1 & 1680 & 122 & 0.56 \\
Rejim 2 & 1140 & 30 & 0.38 \\
Rejim 3 & 180 & 5 & 0.06 \\
\hline \hline
\end{tabular}

Grafik 2'de $\mathrm{MS}(3)-\mathrm{AR}(0)$ modelinin düzgünleştirilmiş ve filtrelenmiş rejim olasıllkları verilmiştir. Grafikte, üçüncü rejim volatilitenin en yüksek, getirinin ise negatif olduğu daralma rejimini göstermektedir. 2009 y1lındaki küresel ekonomik kriz dönemi bu rejimde net bir şekilde görülmektedir. İkinci rejim, volatilitenin üçüncü rejime göre daha az, getirinin ise en yüksek olduğu rejimdir. Bu rejim yoğun bir şekilde, daralma rejiminin etkin olduğu dönemlerin öncesinde ve sonrasında görülmektedir. $\mathrm{Bu}$ dönemlerde, altın getiri serisinin daralma rejimlerinden sonra yüksek getirili ikinci rejimde bulunması, altının yatırımcılar tarafindan kriz sonrası dönemlerde tercih edilen bir yatırım aracı olduğunu açıkça ortaya koymaktadır. Birinci rejim ise getirilerin ve volatilitenin düşük olduğu rejimdir. Ayrıca bu rejim, altın getiri serisinin en çok kaldığı rejimdir. Bu sonuç bize, altın fiyatlarının oynaklığının çok fazla olmadığını ve güvenilir bir yatırım aracı olduğunu göstermektedir. 2016 yılının ortalarından beri, uzun bir süredir altın getiri serisi bu rejimde kalmaktadır. 


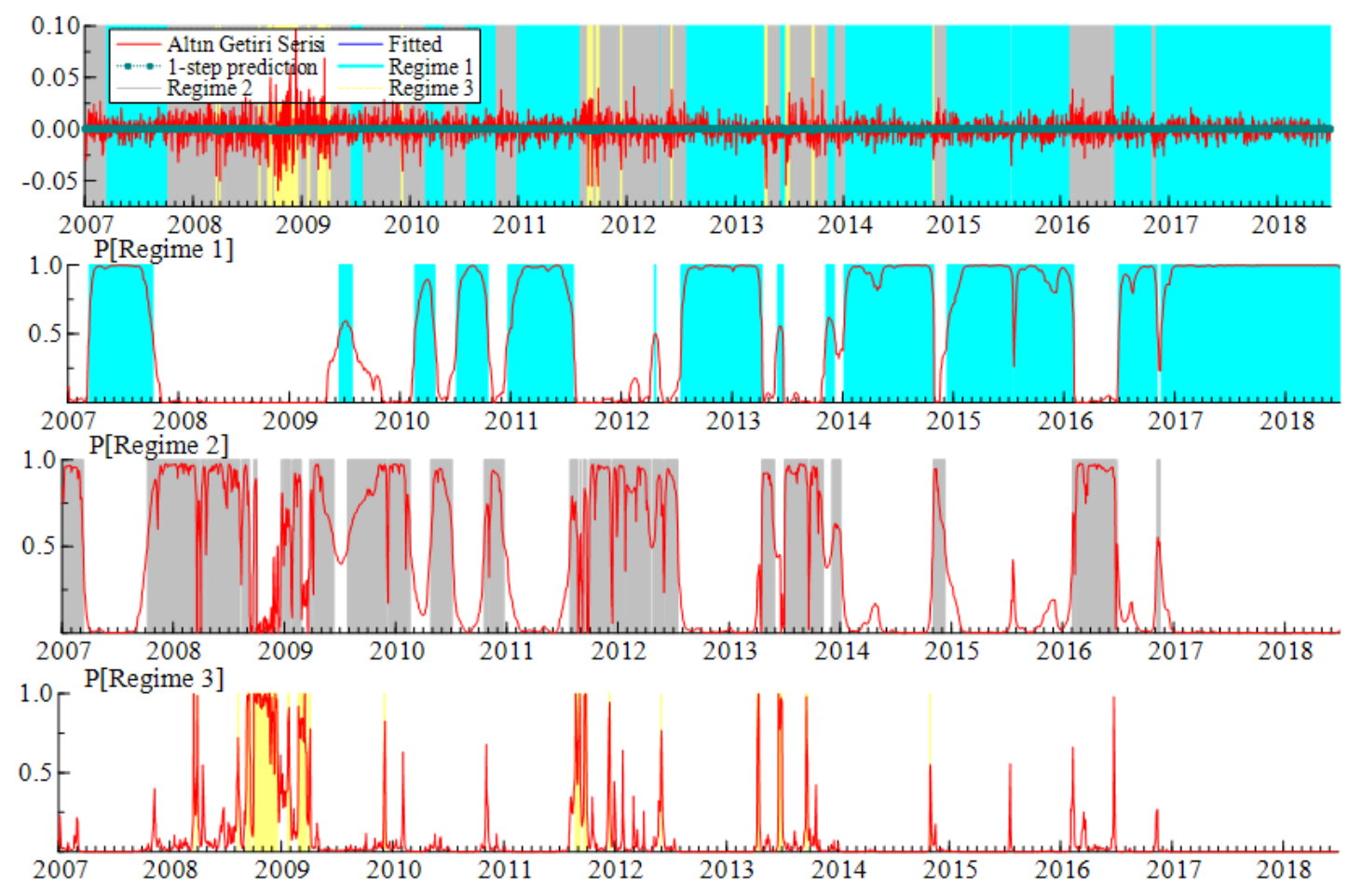

Grafik 2. MSIH(3)-AR(0) Modelinin Rejim Olasılıklar1

\section{SONUÇ}

Önemli bir yatırım aracı olan altının daralma ve genişleme rejimlerinin belirlenmesi, altın getiri serisinin volatilitesi ve öngörülebilirliği açısından yatırımcılara önemli bilgiler vermektedir. Çalışmada, altın getiri serisinin yüksek veya düşük getirili rejimlerde kalma süreleri ve rejimler arası geçiş olasılıkları, üç rejimli bir MS-AR modeli ile analiz edilmiştir.

Modelde, katsayısı negatif olan 3. rejim daralma rejimini gösterirken, katsayıları pozitif olan 1. ve 2. rejim genişleme rejimini göstermektedir. Daralma rejiminin, 2009 yılındaki ekonomik küresel kriz döneminde ve 2011 yılının sonlarında etkili olduğu görülmektedir. Altın getirilerinin en yüksek olduğu ikinci rejim; 2008 yılında, 2009 yılının bir kısmında, 2010, 2012, 2013 yıllarında ve 2016 yılının bir kısmında etkili olmuştur. Volatilitenin ve getirinin düşük olduğu birinci rejim ise, 2007, 2011'in bir kısmı, 2014, 2015 ve 2016 yılının ortalarından başlayarak 2018 yılının ortalarına kadar olan dönemde etkilidir.

Rejim olasılıkları matrisine göre altın getiri serisi, volatilitenin en yüksek, getirinin ise negatif olduğu üçüncü rejimdeyken bir sonraki gözlemde tekrardan üçüncü rejimde olma olasılığ $\%$, volatilitenin üçüncü rejime göre daha düşük, getirinin ise en yüksek olduğu ikinci rejimdeyken bir sonraki gözlemde tekrardan ikinci rejimde olma olasıllğı \%93, volatilitenin ve getirinin ikinci rejime göre daha düşük olduğu birinci rejimdeyken bir sonraki gözlemde tekrardan birinci rejimde olma olasılığ $1 \% 98$ 'dir. Rejim kalıcılığının yüksek olması, yatırımcılar tarafından altın getiri serisinin cari dönemde hangi rejimde olduğunun bilinmesini 
ve bunula birlikte rejimde kalma olasılığg tahmin edilerek, yatırım kararının bu doğrultuda alınabilmesini sağlamaktadır.

Yapılan analizlerin sonucunda, özellikle birçok finansal zaman serilerinin modellenmesinde ve rejimlerin ayrıştırılmasında olduğu gibi BIST altın fiyatları serisinin modellenmesinde de volatilitenin önemli olduğu görülmektedir. Bu nedenle, bundan sonraki yapılacak çalışmalarda, BIST altın fiyatları serisinin volatilite yapısının analiz edilmesi amaçlandığında MS-GARCH modelinin kullanılması önerilmektedir.

\section{KAYNAKLAR}

Akgül, Iş11 - Bildirici, Melike, - Özdemir, Selin (2015), "Evaluating the Nonlinear Linkage between Gold Prices and Stock Market Index Using Markov-Switching Bayesian VAR Models." Prcedia - Social and Behavioral Sciences, 210, pp. 408-415.

Atış, Aydanur Gacener - Erer, Deniz (2018), "The Impact of Monetary Policy on Stock Returns During Bull and Bear Markets: The Evidence From Turkey." Ege Akademik Bakış, 18(4), ss. 699-710

Białkowski, Jedrzej - Bohl, Martin T. - Stephan, P. M., - Wisniewski, Tomasz P. (2015), "The gold price in times of crisis." International Review of Financial Analysis, 41, pp. 329339.

Bildirici, Melike - Alp,A. Elçin - Ersin, Özgür - Bozoklu, Ümit (2010), İktisatta Kullanılan Doğrusal Olmayan Zaman Serisi Yöntemleri, Türkmen Kitapevi, İstanbul.

Büyükyılmaz, Ayça (2015), Markov Rejim Değişimli Vektör Otoregresif ModellerveDoğrusal Olmayan Nedensellik Analizi: OECD Ülkelerinde Yenilenebilir Enerji Tüketimi, CO2 Emisyonuve Ekonomik Büyüme Arasındaki İlişki İçin Bir Uygulama. Akdeniz Üniversitesi Sosyal Bİlimler Enstitüsü, Doktora Tezi.

Clements, Michael P. - Krolzig, Hans-Martin (1997), "A Comparison of the Forecast Performance of Markov-switching and Threshold Autoregressive Models of US GNP." Warwick Economic Research Papers, 489, pp.1-29.

Davies, R. B. - Harte, D. S. (1978), "Hypothesis testing when the nuisance parameter is present only under the alternative." Biometrica, 74, pp. 33-43.

Evci, Samet - Şak, Nazan - Karaağaç, Gökben Adana (2016), "Altın Fiyatlarındaki Değişimin Markov Rejim Değişim Modelleriyle İncelenmesi." Business and Economics Research Journal, 7(4), ss. 67-77.

Goldfeld, Stephen M. - Quandt, Richard E. (1973), "A Markov Model For Switching Regressions." 1, pp. 3-16. 
Guidolin, M. (2011), "Markov Switching Models in Empirical Finance, Missing Data Methods: Time-Series Methods and Applications." Advances in Econometrics, Volume 27 Part 2

Hamilton, James D. (1989), "A New Approach To The Economic Analysis Of Nonstationary Time Series." Econometrica, https://doi.org/10.2307/1912559

Hamilton, James D. (2005), "Regime Switching Models. Macroeconometrics And Time Series Analysis." pp. 1-15.

Koy, Ayben (2017), Vadeli İşlem Piyasaları: BİST30 Endeks Vadeli İşlem Sözleşmesinin Markov Rejim Değişim Modelleri ile Analizi, Derin yayınları, İstanbul.

Lucey, Brian M., - O’Connor, Fergal A. (2013), "Do Bubbles Occur in the Gold Price? An Investigation of Gold Lease Rates and Markov Switching Models." Borsa İstanbul Review, 13(3), pp. 53-63.

Sopipan, Nop, - Sattayatham, Pairote, - Premanode, Bhusana (2012), "Forecasting Volatility of Gold Price Using Markov Regime Switching and Trading Strategy." Journal of Mathematical Finance, 02(01), pp. 121-131.

Tsay, Ruey S. (2006), "Analysis of Financial Time Series." Technometrics, (48). https://doi.org/10.1198/tech.2006.s405

Tuna, Kadir (2014), "Uluslararası Portföy Yönetiminde Rejim Geçişken Karar Destek Modelleri: Gelişmekte Olan Menkul Kıymet Piyasaları Üzerine Bir Uygulama." İşletme ve İktisat Çalışmaları Dergisi, 2(2), ss. 27-43.

Türkmen, Nermin Ceren (2017), Konjonktürel Dalgalanma Modelleri Bağlamında Yeni Monetarist Yaklaşımın MS-VAR Modeli İle Analizi. Yıldız Teknik Üniversitesi Sosyal Bilimler Enstitüsü, Doktora Tezi.

Wai, Phoong Seuk - Ismail, Mohd Tahir - Kun, Sek Siok (2014), "Gold price effect on stock market: A Markov switching vector error correction approach." AIP Conference Proceedings, 1602(August), pp. 990-993.

Yarmohammadi, Masoud - Mostafaei, Hamidreza - Safaei, Maryam (2012), "Markov Switching Models for Time Series Data with Dramatic Jumps." Sains Malaysiana 41(3),(2012), pp. 371-377

Yüksel, Burak (2012), Uluslararası Finansal Krizlerde Altın Fiyatlarının Hareketliliği. Marmara Üniversitesi Sosyal Bİlimler Enstitüsü, Yüksek Lisans Tezi. 
